\title{
THE
}

\section{Food- and Health-Related Correlates of Self-Reported Body Mass Index Among Low-Income Mothers of Young Children}

\author{
Karen McCurdy \\ University of Rhode Island, kmccurdy@uri.edu \\ Tiffani S. Kisler \\ Univerisity of Rhode Island, tkisler@uri.edu \\ Kathleen S. Gorman \\ University of Rhode Island \\ Elizabeth Metallinos-Katsaras
}

Follow this and additional works at: https://digitalcommons.uri.edu/hdf_facpubs

This is a pre-publication author manuscript of the final, published article.

Creative Commons License

c) (†) $\ominus$

This work is licensed under a Creative Commons Attribution-Noncommercial-No Derivative Works 4.0 License.

\footnotetext{
Citation/Publisher Attribution

McCurdy, K., Kisler, T. S., Gorman, K. S., \& Metallinos-Katsaras, E. (2015). Food- and Health-Related Correlates of Self-Reported Body Mass Index Among Low-Income Mothers of Young Children. Journal of Nutrition Education and Behavior, 47(3), 225-233.e1. doi: 10.1016/j.jneb.2015.01.004

Available at: https://doi.org/10.1016/j.jneb.2015.01.004
}

This Article is brought to you for free and open access by the Human Development and Family Science at DigitalCommons@URI. It has been accepted for inclusion in Human Development and Family Science Faculty Publications by an authorized administrator of DigitalCommons@URI. For more information, please contact digitalcommons-group@uri.edu. 


\title{
Food- and health-related correlates of self-reported body mass index among low-income mothers of young children
}

\author{
Karen McCurdy, Ph.D. , \\ Human Development \& Family Studies, University of Rhode Island \\ Tiffani Kisler, Ph.D., \\ Human Development \& Family Studies, University of Rhode Island \\ Kathleen S. Gorman, Ph.D., and \\ Psychology, University of Rhode Island \\ Elizabeth Metallinos-Katsaras, Ph.D., R.D. \\ Nutrition, Simmons College
}

\begin{abstract}
Objective-Examine how income-related challenges around food and health are associated with variation in self-reported maternal body weight among low-income mothers.

Design-Cross-sectional, correlational design. Convenience sample recruited from 7 daycare centers and a Supplemental Nutrition Assistance Program outreach project. Maternal self-report data collected between October 2009 and May 2011.
\end{abstract}

Setting-Two Northeastern cities.

Participants-Sample of 166 mothers; 67\% overweight or obese, 55\% Hispanic, $42 \%$ reporting household food insecurity (HFI).

Main Outcome Measures-Maternal self-reported height and weight to calculate Body Mass Index (BMI). Independent variables: food program participation, supermarket use, 8-item food shopping practices scale, HFI, maternal depressive symptoms, self-rated health (SRH).

Analysis-Hierarchical multiple regression analysis tested relationships between maternal BMI with the independent variables of interest, adjusting for demographic confounds.

Results-Shopping practices to stretch food dollars $(P=.04)$, using community food assistance programs $(P<.05)$, and HFI $(P<.04)$ correlated with heavier maternal BMIs; higher SRH corresponded to lower BMIs $(P=.004)$.

\footnotetext{
(C) 2015 Published by Society for Nutrition Education and Behavior.

* Corresponding author: Karen McCurdy, Ph.D. 2 Lower College Kingston, RI 02881 401-874-5960 Ph 401-874-4020 FAX kmccurdy@uri.edu.

Publisher's Disclaimer: This is a PDF file of an unedited manuscript that has been accepted for publication. As a service to our customers we are providing this early version of the manuscript. The manuscript will undergo copyediting, typesetting, and review of the resulting proof before it is published in its final citable form. Please note that during the production process errors may be discovered which could affect the content, and all legal disclaimers that apply to the journal pertain.
} 
Conclusions and Implications-Some strategies low-income mothers use to manage food resources are associated with heavier BMIs. Nutrition educators, public health practitioners, and researchers need to collaboratively address the associations between these strategies, food insecurity, poor health, and unhealthy weight.

\section{Keywords}

Maternal body mass index; food insecurity; low-income; food shopping practices; self-rated health

\section{Introduction}

Obesity rates for US women increase as income levels decrease, ${ }^{1}$ putting low-income women at higher risk for many of the negative health effects of obesity, including Type II diabetes, cardiovascular disease, and certain cancers. ${ }^{2}$ Research has identified some correlates of unhealthy body weight among females in general; however, the path connecting economic disadvantage to female overweight remains unclear. ${ }^{3}$ The current study addresses this gap by examining how income-related challenges around food and health may be associated with variation in body weight among low-income mothers.

Ensuring an adequate food supply presents a substantial challenge to low-income households, who spend close to one-third of their monthly income on food. ${ }^{4}$ One common strategy to increase food supplies is to apply and receive federal food assistance through the Supplemental Nutrition Assistance Program (SNAP) and/or the Special Supplemental Nutrition Program for Women, Infants and Children (WIC). Research has investigated the association between SNAP participation and overweight/obesity among women with some studies reporting positive associations, ${ }^{5-7}$ and others finding no association. ${ }^{8,9}$ In contrast, relatively few studies have investigated the association between participation in WIC and maternal weight though WIC benefits influence the amount and quality of food available to mothers. ${ }^{10}$ Low-income families also may seek food from community food programs, such as soup kitchens and food banks, as another strategy to increase food supplies. ${ }^{11,12}$ Research found that food from soup kitchens had poor nutritional content, ${ }^{13}$ which could contribute to unhealthy weight.

Access to affordable healthy food presents a challenge for women living in poor neighborhoods as poor neighborhoods tend to have fewer supermarkets than more advantaged neighborhoods. ${ }^{14}$ Limited supermarket access, typically defined by physical proximity to the nearest supermarket or grocery store, ${ }^{15}$ has been associated with overweight and obesity in many ${ }^{16,17}$ but not all ${ }^{15,18}$ studies. These discordant findings may arise because measures of neighborhood supermarket proximity may not capture actual supermarket access and use. ${ }^{15}$

Low-income families also report utilizing a range of food shopping practices to stretch food resources, such as buying food in bulk and using coupons. ${ }^{11,19,20}$ Such food shopping practices to manage food dollars have been associated with greater availability and consumption of important nutrients in households receiving SNAP benefits, ${ }^{20}$ and could be related to weight among low-income women. 
Limited access to sufficient food can lead to food insecurity, especially among low-income households. ${ }^{21}$ Food insecurity is defined as uncertain or inadequate access to sufficient and safe nutrition, or limited ability to obtain such nutrition through socially appropriate means. ${ }^{22}$ Food insecurity has been associated with increased maternal weight among women overall. ${ }^{23}$ Further, food insecure women with children were found to have higher weight compared to food-insecure women without children. ${ }^{8}$ Some hypothesize that the stress associated with food insecurity may function as a pathway to unhealthy eating and weight gain among low-income mothers. ${ }^{24,25}$

Finally, low income has negative associations with health including higher levels of depression for adult women ${ }^{26}$ and poorer physical health. ${ }^{27}$ In turn, depression has been positively associated with food insecurity ${ }^{23,28}$ and obesity among adult females, ${ }^{29,30}$ and poor self-rated health has been identified as a consequence and predictor of excess body weight for white and black women. ${ }^{31}$ Because most of these studies analyzed data from nationally representative samples ${ }^{23,26,29,31}$ and/or compared mean differences between income groups, ${ }^{23,27,31}$ it is unclear whether these health indicators are associated with variation in BMI among low- income women.

The current study seeks to address these gaps by examining food- and health-related correlates of weight in an ethnically diverse sample of low-income mothers. First, the study investigated whether participation in food assistance programs (e.g., SNAP, WIC, community food programs), supermarket use, food shopping practices, and food insecurity were correlated with maternal weight. Next, the study examined whether self-reported mental and physical health challenges more commonly faced by low-income women were associated with unhealthy body weight.

\section{Methods}

\section{Sample and Procedures}

The data for these analyses were derived from a cross-sectional study designed to investigate factors contributing to food insecurity and obesity among low-income 2-5 year old children. ${ }^{32}$ The current study included a convenience sample of 166 mothers recruited from 7 preschools serving low-income urban neighborhoods, as well as a SNAP outreach project. Data were collected between October 2009 and May 2011. A priori power analyses demonstrated that a sample size of 150 was sufficient for measuring moderately strong regression effects with up to 13 covariates.

Research staff recruited families directly from the 8 sites during peak parent flow times. After obtaining informed consent, bilingual research staff administered the parent self-report measures. These assessments lasted 30-40 minutes. Participants were paid \$20 for their study involvement. The Institutional Review Board at the University of Rhode Island approved all procedures. Over 200 mothers were approached by researchers with 174 mothers agreeing to participate in the study and completing the surveys. Of this group, 8 participants were excluded because they did not provide data on weight $(n=4)$ or height $(n$ =4). The final sample consisted of 166 mothers. 


\section{Constructs and Measures}

Participants completed a demographic and health questionnaire, and measures assessing the use of food assistance programs, use of supermarkets, food shopping practices, household food security status, depression, and self-rated health. Constructs and measures are described below.

Body Mass Index-Maternal self-report was used to calculate Body Mass Index (BMI). Mothers were asked to report their height to the nearest inch and weight to the nearest pound. The following formula ${ }^{33}$ was used to calculate BMIs: weight (lb)/[height (in) $]^{2}$ * 703. According to the World Health Organization, adult BMIs $>25$ and $<30$ are considered overweight. BMIs > 30 meet the definition of obese. ${ }^{34}$

Food program participation-Participants completed a modified version of the Current Population Survey Food Security Supplement (FSS). ${ }^{35}$ Items from 3 of the 5 FSS modules were adapted for use. A fourth module, the Food Security Core Module (FSCM), was administered in its entirety and is described below. With the exception of the FCSM, all FSS items are individually analyzed. The FSS data have been used to create national estimates of use of federal and community food assistance programs. ${ }^{35}$ The current study adapted 2 individual items assessing participation in SNAP and WIC from the 10-item Food Program Participation Module of the FSS that assesses all federal food assistance programs. Participants were asked whether anyone in the household had received WIC $(1=$ yes; $0=$ no) or SNAP $(1=$ yes; $0=$ no) in the past 30 days. Two items assessing participation in community food programs were drawn from FSS Ways of Coping Module, a 9-item questionnaire that assesses 12 month and 30 day past use of emergency food, use of programs providing food for seniors, use of soup kitchens/shelters, and availability of these resources. Participants were asked about receipt of emergency food from a church, food pantry, food bank or community cupboard, and about receipt of meals at a soup kitchen, church or other community meal site. Both items referred to the previous 30 days. Any receipt of community food was coded as yes (1); no receipt was coded as 0.

Supermarket Use-To assess shopping at supermarkets and grocery stores, the study adapted 2 items from the 11-item Food Expenditures Module of the FSS, a validated measure of household spending on food. ${ }^{36}$ This module includes 3 items that ask whether respondents shopped at certain types of stores (e.g., supermarkets/grocery stores, stores other than supermarkets, restaurants), in the past 7 days, followed by "Did you/anyone in your household buy food from any other kind of place LAST WEEK?" The remaining items ask how many times respondents shopped at those types of store, and how much was spent on food and non-food items. The current study adapted the item that allowed respondents to name the store: "Can you tell me all of the places where you or someone in your household bought food during the last week?" with the follow-up question about times shopped in past week at each named store. A research assistant coded the supermarket/grocery store status of each response ( $1=$ yes supermarket; $0=$ not a supermarket). The number of times shopped in past week at each store designated as a supermarket or grocery store was combined to create the number of times shopped at a supermarket variable. If no supermarket or grocery store was named, number of times shopped at supermarket $=0$. 
Food Shopping Practices-As part of a broader study of family food behaviors, a pilot survey of shopping practices to stretch food dollars was administered to 38 mothers of children ages 2-11 recruited from 2 day care centers and 2 food outreach programs serving low-income neighborhoods in a Northeastern city. A detailed description of the study procedures is reported elsewhere. ${ }^{32}$ Based on focus group research with low-income mothers, ${ }^{11,19}$ the initial food shopping practices survey asked respondents how frequently they used 3 practices to stretch food dollars: used food coupons, bought food in bulk, and shopped for food at a certain store because of a sale. These items were followed by an openended question "Are there any other strategies you use to help feed your family and save money?" Cognitive interviews with an initial subsample of 5 of these mothers indicated that respondents had no difficulty understanding the questions and the 4-point Likert Scale response set. Results from the open-ended question identified 4 additional food shopping practices used by these mothers: bought lower cost food to save money, bought less junk food, went to 2 or more stores to find cheaper foods, and used a shopping list. Research suggesting that low-income families will buy cheaper energy dense food over more expensive fruits and vegetables ${ }^{37}$ led to the addition of the final item: bought fewer fruits and vegetables to save money.

The final 8-item Food Shopping Practices scale asked participants to rate their use of these strategies on a 4 -point Likert scale $(1=$ never; $4=$ often $)$ in the previous 30 days. These items were summed into a scale that achieved acceptable internal reliability $(a=.71)$. Four respondents were each missing 1 item from this scale, or $12.5 \%$ of scale items. As missing data accounted for less than $20 \%$ of the scale items, person-means were substituted for the missing items in the scale in the following manner: all available responses were summed, then divided by the number of items answered. The final scale ranged from 1 to 4 , with higher scores indicating more frequent use of these shopping strategies. The use of personmean imputation on scale items has been found to produce acceptable Kappas when missing values are low, as was the case here. ${ }^{38}$

Food Security Status-Parents completed the Food Security Core Module ${ }^{39}$ (FSCM), considered the "gold standard" for measuring household food security in the US. ${ }^{40}$ The FSCM consists of 18 items that examine the household's perception of access to sufficient amounts and types of food during the previous 12 months (e.g., "we couldn't afford to eat balanced meals"). The current study also utilized the standardized Spanish-language version for Spanish-speaking participants, developed and validated with focus groups. ${ }^{41}$ Reliability and validity for the 18-item FSCM is high $(\alpha=.86-.93) .{ }^{42}$ In accordance with standard protocols developed by US Department of Agriculture, households responding with 2 or fewer affirmative responses were classified as food secure; those with 3 or more affirmative responses were classified as food insecure. ${ }^{39}$

Health Indicators-Maternal mental health was assessed with the Center for Epidemiologic Studies Depression Scale ${ }^{43}$ (CES-D), a 20-item self-report instrument that screens for the presence of depressive symptoms in the previous week. Participants rate each item on a 4-point rating scale, with a maximum score of 60 . Higher scores indicate greater levels of depressive symptoms. This brief, widely used screening measure has achieved high 
internal consistency for both the English $(\alpha>.84)$ and Spanish $(\alpha=.90)$ versions. ${ }^{44,45}$ Analysis of CES-D scores indicated acceptable internal reliability $(a=.88)$ in the current sample.

Mothers completed a single item self-rated health measure, with 5 response categories ranging from excellent health (5) to poor health (1). ${ }^{46}$ This single item measure is the most frequently used health assessment in the $\mathrm{US}^{47}$ and possesses strong predictive validity for mortality and morbidity. ${ }^{48}$

Covariates-To adjust for other potential biological and socio-cultural confounds of maternal weight and income status, the following variables from the demographic and health questionnaire were considered: Breastfeeding status $(1=$ ever breastfed; $0=$ never breastfed); number of adults in household; partner/marital status ( $1=$ married or lives with partner; $0=$ no partner/spouse); maternal age in years; maternal ethnicity $(1=$ Hispanic; $0=$ Non-Hispanic); primary home language ( $1=$ Spanish; $0=$ English); maternal education in years; and maternal employment $(1=$ yes; $0=$ no). Monthly household income was collected in 7 increments of $\$ 500$, ranging from 0 - $\$ 500$, to $\$ 4,000$ and above. Due to small cell sizes in 4 categories $(n<20)$, the original 7 categories were collapsed into 3 categories with roughly equivalent numbers of participants $(n>40)$ in each category $(<\$ 1,000 ; \$ 1,001$ $\$ 1,500 ;>\$ 1,500)$.

Statistical Analyses-Data were analyzed with SPSS v. 21 (IBM, Armonk, NY, 2013). Preliminary analyses tested variables for normality and multicollinearity. This analyses revealed acceptable correlations among independent variables $(r<.50)^{49}$ and normal distributions (skew < 1.4). ${ }^{50}$ An improbable value was found for number of times shopped at supermarket in the past week (9) for a participant who also noted shopping only a few times a month for food. This value was recoded as missing. Bivariate analyses, utilizing correlations and t-tests, identified significant $(P<.05)$ relationships between the covariates and BMI to include in the multiple regression model.

Next, hierarchical multiple regression analysis was used to test the hypothesis that maternal BMI is a function of food program participation, supermarket usage, food shopping practices, food security status, and self-reported health indicators. To adjust for other confounds of weight, Model 1 entered all socio-demographic covariates identified as significant in the bivariate comparisons. Next, the food- and health-related variables were entered using forward stepwise regression to identify significant relationships. The combined contribution of the significant food- and health-related variables was assessed by examining the amount of additional model variance explained by Model 2 (Adjusted $R^{2}$ change), and the individual significance level of each variable in the overall model. Acceptable results of the variance inflation factor, and collinearity tolerance, suggested that the estimated $\beta$ s were well established in the regression model. Significance was set at $P<$. 05 . Missing data were minimal with 1 data point missing for 2 respondents. The regression results were unchanged when the missing data were excluded $(n=164)$ or the mean was substituted for missing data $(n=166)$. The latter model is presented. Post hoc chi-square analyses with Bonferroni's correction examined whether receipt of community food varied by any socio-demographic variable. 


\section{Results}

\section{Descriptive Analyses}

As shown in Table 1, the majority of mothers were single (63\%), of Hispanic ancestry (55\%), and earned less than $\$ 1,500$ per month (60\%). Overall, $66 \%$ of mothers met the WHO definition of overweight or obese. ${ }^{34}$ Food insecurity was prevalent (42\%) while close to one-quarter of mothers scored at or above the CES-D depression screening cutoff of $16 .{ }^{44}$

Participation in government food assistance programs was high with $80 \%$ reporting receipt of SNAP and/or WIC benefits. In contrast, only $17 \%$ received assistance from community food programs. Preliminary analyses identified 2 demographic variables that were significantly associated with maternal BMI. Mothers who primarily spoke Spanish in the home had lower BMIs $(m=26.9, S D=5.8)$ than those who did not $(m=29.7, S D=7.8 ; t=$ $4.8, P=.03)$. Maternal BMI was positively correlated with number of other adults in the home $(r=.189, P<.02)$.

Some significant bivariate associations were found among the food- and health-related variables. Mothers in food insecure households reported more frequent use of food shopping practices to stretch food dollars $(t=-2.48, P=.01)$, and higher CES-D scores $(t=2.26, P$ $<.02)$, than mothers in food secure households. CES-D scores were negatively associated with mother's self-rated health $(r=-.299, P=.003)$, and were higher among mothers receiving SNAP benefits as compared to those who did not $(t=2.41, P<.02)$.

\section{Multivariate Analyses}

The results of the hierarchical multivariate regression analyses with all significant predictors are shown in Table 2. Model 1 indicated that demographic variables accounted for $7 \%$ of the variance (adjusted $R^{2}=.06$ ), which was significantly different from zero $(P=.003)$.

Maternal BMI was positively associated with the number of other adults living in the home $(P=.009)$ and negatively associated with Spanish as the primary language in the home $(P$ $<.02)$.

The significant food- and health-related variables were added to the regression equation in Model 2. Taken together, these variables significantly increased the amount of explained variance in maternal BMI over Model $1\left(R^{2} \Delta=.13 ; F \Delta_{(4,159)}=6.48, P=.000\right)$. After adjusting for type of language spoken in the home and number of adults in the household, 3 variables related to food resources were significantly associated with maternal BMIs. Any use of community food programs $(P<.05)$, more frequent use of food shopping practices to stretch food dollars $(P=.04)$, and household food insecurity $(P<.04)$ had positive associations with BMI for these low-income women. In contrast, participation in WIC or SNAP, and number of weekly shopping trips to supermarkets did not emerge as significant correlates of maternal BMI.

In terms of health indicators, maternal self-rated health $(P=.004)$ was significantly associated with BMI such that mothers reporting better health had lower BMIs. Of all the independent variables, self-rated health had the largest standardized regression coefficient (Beta $=-.211)$. Depressive symptoms, as measured by CES-D scores, were not significantly 
associated with maternal BMI. The final equation accounted for $17 \%$ of the variance in BMI.

To assess whether unmeasured constructs related to very low-income might explain some of the above relationships, the multiple regression analyses were rerun with 2 dummy variables representing the 3 levels of household income (monthly household income < $\$ 1000$ vs. > $\$ 1,500$; monthly household $\$ 1000$ to $\$ 1,500$ versus $>\$ 1,500$ ). The income variables did not significantly predict BMI scores, nor did any of the other associations change (not shown). As only $17 \%$ of the sample used a community food program, post hoc chi-square analyses with Bonferroni's correction examined whether any socio-demographic variables were associated with use of this food source. These analyses revealed that households with monthly incomes under $\$ 1,500$ were significantly more likely to use community food programs as compared to households with incomes over $\$ 1,500\left(86 \%\right.$ vs $14 \% ; \chi^{2}=8.9, P$ $=.003)$.

\section{Discussion}

This study reports associations between shopping practices to stretch food resources, such as using coupons, buying in bulk, and shopping for sales, and heavier maternal BMIs, addressing gaps in previous research studies that did not assess the relationship between shopping strategies and maternal body weight or consumption of unhealthy foods. ${ }^{20}$ At least one plausible pathway may explain this relationship. Because poor mothers seek low-cost items that will not spoil, ${ }^{51}$ these mothers may be more likely to make bulk or sale purchases of energy dense, nonperishable foods, such as soft drinks, cereals, cookies, pasta packages and potato chips, rather than lower calorie items that are perishable such as fruits and vegetables. Larger inventories of unhealthy food in the home have been associated with greater consumption of fat, ${ }^{52}$ which may lead to unhealthy BMIs.

This study simultaneously examined the associations between maternal body weight with participation in SNAP, WIC, and community food assistance programs. Consistent with research noting poor diets among food pantry participants ${ }^{53}$ and low nutritional value of food provided through community food assistance programs, ${ }^{13}$ use of community food resources was positively associated with maternal BMIs in this sample of low-income mothers. Clearly, community food programs provide essential resources to families; however, it is unknown if reliance on these emergency food sources to meet nutritional needs may be contributing to unhealthy weight among low-income mothers. As noted earlier, only $17 \%$ of the sample reported using a community food program. Further, income and use of community food programs were significantly correlated. Thus, unobserved differences related to very low-income may account for the association between maternal body weight and use of community food programs.

In contrast, receipt of SNAP or WIC was not associated with maternal body weight. The results regarding SNAP contradict many studies in this area, ${ }^{5,6}$ but are consistent with Ver Ploeg and colleagues' finding that BMI differences between SNAP recipients and nonrecipients have diminished. ${ }^{9}$ The null findings around WIC echo those of Martin and Lippert's ${ }^{8}$ national study and add to the limited empirical knowledge regarding the 
association between participation in WIC and maternal BMI. Because these data are crosssectional, the effects of earlier or persistent participation in government food assistance programs are not known. Further, the study did not collect data on the amount of SNAP/WIC benefits, an important consideration as some research has associated lower SNAP benefits with heavier BMIs among women. ${ }^{54}$

Rates of weekly shopping at supermarkets were not significantly associated with maternal BMI. Research on the relationship between neighborhood supermarket access and healthier body weight is mixed. ${ }^{14,15}$ The current study adds to the literature as it assessed actual weekly use of supermarkets by these mothers as opposed to supermarket proximity. Importantly, the vast majority of these urban mothers (88\%) shopped at least once at a supermarket in the previous week. Although weekly supermarket shopping rates varied among these mothers $(m=2.1, S D=1.6)$, the high utilization of this food source may explain the null findings.

Consistent with prior research, ${ }^{8}$ mothers reporting food insecurity had significantly higher BMIs than mothers who were food secure. Frongillo and Bernal have hypothesized that maternal weight gain may result from the stress associated with food insecurity. ${ }^{24}$ Stress, such as that stemming from inadequate access to food, leads to increased cortisol secretion, which is associated with greater caloric intake and weight gain. ${ }^{55}$ Further, acute stress is believed to alter one's metabolic and stress response system in ways that increase the likelihood of eating unhealthy foods, and binge eating when food is available. ${ }^{26}$ It also is possible that food insecure mothers reserve higher quality household food for their children, resulting in a poorer diet for themselves.

In terms of health indicators, mothers who rated their own health more highly had significantly lower BMIs than mothers giving lower self-ratings of health. Indeed, this factor emerged as the most significant individual correlate of maternal BMI for these low-income mothers. Self-rated health has been found to better predict actual health and potential undiagnosed health problems, as compared to diagnostic tools. ${ }^{31}$ Thus, self-rated health is believed to capture bodily perceptions that indicate problematic functioning that cannot be discerned through more standard clinical assessments. ${ }^{47}$ However, it remains unclear whether self-rated health predicts or is a consequence of maternal BMI.

Maternal depressive symptoms did not correlate with maternal BMI. These findings are inconsistent with previous studies that document an association between depression and subsequent increases in BMI. ${ }^{56,57}$ A recent national study, however, found no association between depression and weight status among Mexican-American and black, non-Hispanic women though this relationship was observed among non-Hispanic white women. ${ }^{58}$ Because depressed Hispanics are more likely to report decreased appetite as compared to depressed non-Hispanics, ${ }^{59}$ it is possible that the CES-D depression measure, which contained only 1 item assessing appetite, was not sensitive enough to detect this common depressive symptom among Hispanics. Further, Hispanic subgroups have been found to present depression in the form of physical symptoms or somatic complaints, ${ }^{60}$ which may complicate the detection and diagnosis of depression among this population. 


\section{Limitations}

Study strengths include examining a variety of strategies and resources to access and manage food supplies, and the use of a low-income sample that includes a high portion of Hispanics (55\%), an understudied group. However, some limitations should be kept in mind. First, the sample consisted of urban, Northeastern mothers with high rates of employment; thus the findings may not apply to other low-income populations. Even though $80 \%$ of families participated in WIC and/or SNAP, selection bias cannot be ruled out as unobserved variables that relate to participation in food assistance programs and maternal weight may exist, such as acculturation status. Maternal BMIs were calculated with self-report data. This methodology is frequently used in studies assessing income and weight, ${ }^{61,62}$ but has been found to produce underestimates of BMI. ${ }^{63}$ Self-report was used to assess all constructs of interest, and may inflate the likelihood of identifying significant relationships in the regression analysis. As the data are cross-sectional with some measures covering different time frames (i.e., last week vs. last 30 days), the specific direction of effects cannot be determined. A priori power analyses indicated that the sample size was adequate for detecting moderately strong regression effects; however, the size may have been insufficient for discerning less powerful but important relationships. Finally, the predictor variables explained $17 \%$ of the variance in maternal BMIs, a significant but relatively low percentage.

\section{Implications for Research and Practice}

The results suggest strategies mothers employ to increase and manage food resources, including strategically stretching food dollars and using community food programs, are associated with heavier BMIs. Future research needs to better elucidate the relationships between these strategies and maternal weight. The food shopping practices scale demonstrated acceptable internal reliability and was associated with maternal BMI. Although preliminary, these results support validating this scale with other low-income populations. Future studies should collect qualitative data on the specific food shopping practices that are associated with weight to help nutrition educators guide low-income families toward healthy and cost saving choices. The study results also suggest that greater attention to the use of community food programs is needed. Longitudinal research should examine the frequency, amount, and timing of receipt of food resources to clarify how participation in federal and community food programs might be associated with weight.

Beyond these strategies to increase and manage food resources, household food insecurity was associated with heavier maternal BMIs. The provision of nutrition education to SNAP participants has been identified as an effective way to increase food security, especially for households with an employed adult. ${ }^{64}$ Research should investigate whether such education also results in healthier weights for low-income mothers experiencing food insecurity. The single item self-rating of health question had particular salience as a correlate of BMI among this low-income group. Further, low self-rated health has been found to predict decreased physical activity among low-income adults. ${ }^{65}$ These findings draw attention to the importance of longitudinal research to identify the direction of the associations between selfrated health, food insecurity, and maternal BMI. From a practice perspective, the study results highlight the need for increased collaboration among nutrition educators, public 
health practitioners, and researchers to better address the pathways to unhealthy weight among low-income mothers.

\section{Acknowledgements}

This research was supported by award number RO3HD05524 from the Eunice Kennedy Shriver National Institute of Child Health and Human Development. The content is solely the responsibility of the authors and does not necessarily represent the official views of the Eunice Kennedy Shriver National Institute of Child Health and Human Development or the National Institutes of Health. The authors would like to Kristen Guertin and Stephen Favasuli for their assistance with data collection and management.

\section{References}

1. Ogden, C.; Lamb, M.; Carroll, M.; Flegal, K. NCHS Data Brief, No. 50. National Center for Health Statistics; Hyattsville, MD: 2010. Obesity and socioeconomic status in adults: United States, 2005-2008..

2. Guh D, Zhang W, Bansback N, Amarsi Z, Brimingham CL, Anis A. The incidence of comorbidities related to obesity and overweight: a systematic review and meta-analysis. BMC Public Health. 2009; 9:88. [PubMed: 19320986]

3. McFarlane A, Abbott G, Crawford D, Ball K. Personal, social and environmental correlates of healthy weight status amongst mothers from socioeconomically disadvantaged neighborhoods: findings from the READI study. Int J Behav Nutr Phys Act. 2010; 7:23-31. [PubMed: 20331900]

4. Blisard, N.; Stewart, H. Economic Information Bulletin No. 23. U.S. Department of Agriculture, Economic Research Services; Washington, DC: 2007. Food spending in American households, 2003-2004..

5. Leung C, Willett W, Ding E. Low-income Supplemental Nutrition Assistance Program participation is related to adiposity and metabolic risk factors. Am J Clin Nutr. 2012; 95:17-24. [PubMed: 22170370]

6. Zagorsky J, Smith P. Does the U.S. Food Stamp Program contribute to adult weight gain? Econ Hum Biol. 2009; 7:246-258. [PubMed: 19540176]

7. Zhang Q, Chen Z, Diawara N, Wang Y. Prices of unhealthy foods, food stamp program participation, and body weight status among U.S. low-income women. J Fam Econ Iss. 2011; 32:245-256.

8. Martin M, Lippert A. Feeding her children, but risking her health: the intersection of gender, household food insecurity and obesity. Soc Sci Med. 2012; 74:1754-1764. [PubMed: 22245381]

9. Ver Ploeg M, Mancino L, Lin B-H, Wang C-Y. The vanishing weight gap: trends in obesity among adult food stamp participants (US) (1976-2002). Econ Hum Biol. 2007; 5:20-36. [PubMed: 17113841]

10. Odoms-Young A, Kong A, Schiffer L, Porter S, Blumstein L, Bess S, Berbaum M, Fitzgibbon M. Evaluating the initial impact of the revised Special Supplemental Nutrition Program for Women, Infants, and Children (WIC) food packages on dietary intake and home food availability in African-American and Hispanic families. Public Health Nutr. 2013; 17:83-93. [PubMed: 23544992]

11. Kempson K, Keenan D, Sadani P, Adler A. Maintaining food sufficiency: coping strategies identified by limited-resource individuals versus nutrition educators. J Nutr Educ Behav. 2003; 35:179-188. [PubMed: 12859882]

12. Wiig Dammann K, Smith C. Factors affecting low-income women's food choices and the perceived impact of dietary intake and socioeconomic status on their health and weight. J Nutr Educ Behav. 2009; 41:242-253. [PubMed: 19508929]

13. Lyles C, Drago-Ferguson S, Lopez A, Seligman H. Nutritional assessment of free meal programs in San Francisco. Prev Chronic Dis. 2013; 10:120301.

14. Larson N, Story M, Nelson M. Neighborhood environments: disparities in access to healthy foods in the U.S. Am J Prev Med. 2009; 36:74-81. [PubMed: 18977112] 
15. Drewnowski A, Aggarwal A, Hurvitz P, Monsivais P, Moudon A. Obesity and supermarket access: proximity or price? Am J Public Health. 2012; 102:e74-e-80. [PubMed: 22698052]

16. Han E, Powell L, Isgor Z. Supplemental nutrition assistance program and body weight outcomes: the role of economic contextual factors. Soc Sci Med. 2012; 74:1874-1881. [PubMed: 22486839]

17. Bodor JN, Rice J, Farley T, Swalm C, Rose D. The association between obesity and urban food environments. J Urban Health. 2010; 87:771-781. [PubMed: 20458548]

18. Ford P, Dzewaltowski D. Neighborhood deprivation, supermarket availability, and BMI in lowincome women: A multilevel analysis. J Community Health. 2011; 36:785-796. [PubMed: 21547411]

19. Hoisington A, Shultz J, Butkus S. Coping strategies and nutrition education needs among food pantry users. J Nutr Educ Behav. 2002; 34:326-333. [PubMed: 12556271]

20. Hersey J, Anliker J, Miller C, Mullis R, Daugherty S, Das S, et al. Food shopping practices are associated with dietary quality in low-income households. J Nutr Educ. 2001; 33:S16-S26. [PubMed: 12857541]

21. Coleman-Jensen, A.; Nord, M.; Singh, A. Economic Research Report No. ERR-155. U.S. Department of Agriculture, Economic Research Service; Washington, DC: 2013. Household food security in the United States in 2012 ..

22. Anderson SA. Core indicators of nutritional state for difficult-to-sample populations. J. Nutr. 1990; 120:1559-1600. [PubMed: 2243305]

23. Beydoun M, Wang Y. Pathways linking socioeconomic status to obesity through depression and lifestyle factors among young US adults. J Affective Disord. 2010; 123:52-63.

24. Frongillo E, Bernal J. Understanding the coexistence of food insecurity and obesity. Curr Pediatr Rep. 2014; 2:284-290.

25. Sinha R, Jastreboff A. Stress as a common risk factor of obesity and addiction. Biol Psychiatry. 2013; 73:827-835. [PubMed: 23541000]

26. Ertel K, Rich-Edwards J, Koenen K. Maternal depression in the Unites States: nationally representative rates and risks. J Women's Health. 2011; 11:1609-1617.

27. Benjamins MR, Hirschman J, Hirschtick J, Whitman S. Exploring differences in self-rated health among Blacks, Whites, Mexicans, and Puerto Ricans. Ethn Health. 2012; 17:463-476. [PubMed: 22288772]

28. Leung C, Epel E, Willett W, Rimm E, Laraia B. Household food insecurity is positively associated with depression among low-income supplemental nutrition assistance program participants and income-eligible nonparticipants. J Nutr. 2015 DOI: 10.3945/jn.114.199414.

29. Pratt, L.; Brody, D. NCHS Data Brief, No 167.. National Center for Health Statistics; Hyattsville, MS: 2014. Depression and obesity in the U.S. adult household population, 2005-2010..

30. Luppino F, DeWit L, Bouvy P, Stijnen T, Cuijperes P, Penninx B, Zitman F. Overweight, obesity, and depression: a systematic review and meta-analysis of longitudinal studies. Arch Gen Psychiatry. 2010; 67:220-229. [PubMed: 20194822]

31. Zajacova A, Burgard S. Body weight and health from early to mid-adulthood: a longitudinal analysis. J Health Soc Behav. 2010; 51:92-107. [PubMed: 20420297]

32. McCurdy K, Gorman K, Kisler T, Metallinos-Katsaras E. Associations between family food behaviors, maternal depression, and child weight among low-income children. Appetite. 2014; 79:97-105. [PubMed: 24768937]

33. Centers for Disease Control and Prevention. [June 13, 2013] About BMI for Adults. http:// www.cdc.gov/healthyweight/assessing/bmi/adult_BMI/index.html\#Interpreted.

34. World Health Organization (WHO). Obesity: Preventing and Managing the Global Epidemic. WHO; Geneva: 2000. WHO Technical Report Series, No. 894

35. Nord, M.; Andrews, M.; Carlson, S. Economic Research Report No. ERR-66. US Department of Agriculture, Economic Research Service; Washington DC: 2008. Household food security in the United States, 2007..

36. Oliveira, V.; Rose, D. Economic Research Service. US Department of Agriculture; Washington, DC: 1996. Food expenditure estimates from the 1995 CPS Food Security Supplement: how do they compare with the Consumer Expenditure Survey?. Staff Paper No. AGES 9617 
37. Darmon N, Drewnowski A. Does social class predict diet quality? Am J Clin Nutr. 2008; 87:110717. [PubMed: 18469226]

38. Shrive F, Stuart H, Quan H, Ghali W. Dealing with missing data in a multi-question depression scale: a comparison of imputation methods. BMC Med Res Methodol. 2006; 6:57-66. [PubMed: 17166270]

39. Bickel, G.; Nord, M.; Price, C.; Hamilton, W.; Cook, J. Guide to Measuring Household Security, revised 2000. US Department of Agriculture, Food and Nutrition Service; Washington, DC: 2000.

40. Hager E, Quigg A, Black M, Coleman S, Heeren T, Rose-Jacobs R, Cook J, et al. Development and validity of a 2-item screen to identify families at risk for food insecurity. Pediatrics. 2010; 126:e26. DOI: 10.1542/peds.2009-3146. [PubMed: 20595453]

41. Harrison G, Stormer A, Herman D, Winham D. Development of a Spanish-language version of the U.S. Household Food Security Survey Module. J Nutr. 2003; 133:1192-1197. [PubMed: 12672942]

42. Carlson S, Andrews M, Bickel G. Measuring food insecurity and hunger in the United States: development of a national benchmark measure and prevalence estimates. J Nutr. 1999; 129:510S516S. [PubMed: 10064320]

43. Radloff L. The use of the Center for Epidemiologic Studies Depression Scale in adolescents and young adults. J Youth Adolesc. 1991; 20:149-166. [PubMed: 24265004]

44. Radloff L. The CES-D scale: A self-report depression scale for research in the general population. Appl Psychol Meas. 1977; 1:385-401.

45. Gonzalez V, Stewart A, Ritter P, Lorig K. Translation and validation of arthritis outcome measures into Spanish. Arthritis Rheum. 1995; 38:1429-1446. [PubMed: 7575693]

46. Spernak S, Schottenbauer M, Ramey S, Ramey C. Child health and academic achievement among former Head Start children. Child Youth Serv Rev. 2006; 28:1251-1261.

47. Jylhä M. What is self-rated health and why does it predict mortality? Towards a unified conceptual model. Soc Sci Med. 2009; 69:307-316. [PubMed: 19520474]

48. Brunner R, Stefanick M, Aragaki A, Beresford S, Hubbell FA, LaCroix A, et al. Self-rated health and medical outcomes in the Women's Health Initiative: the aging continuum, health, morbidity, mortality. J Gerontol Geriat Res. 2013; 3:1000139.

49. Hair, JF., Jr; Black, W.; Babin, B.; Anderson, R.; Tatham, R. Multivariate Data Analysis. 6th ed.. Pearson Education; Upper Saddle River, NJ: 2006.

50. Kline, R. Principles and Practice of Structural Equation Modeling. 3rd ed.. Guilford Press; New York: 2011.

51. Morton J, Guthrie JF. Diet-related knowledge, attitudes, and practices of low-income individuals with children in the household. Fam Econ Nutr Review. 1997; 10:2-15.

52. Kegler M, Alcantara I, Haardorfer R, Gazmararian J, Ballard D, Sabbs D. The influence of home food environments on eating behaviors of overweight and obese women. J Nutr Educ Behav. 2014; 46:188-196. [PubMed: 24809866]

53. Robaina D, Martin K. Food insecurity, poor diet quality, and obesity among food pantry participants in Hartford, CT. J Nutr Educ Behav. 2013; 45:159-164. [PubMed: 23219294]

54. Jilcott S, Wall-Bassett E, Sloane B, Moore J. Associations between food insecurity, Supplemental Nutrition Assistance Program benefits, and body mass index among adult females. J Am Diet Assoc. 2011; 111:1741-1745. [PubMed: 22027058]

55. Foss B, Dyrstad S. Stress in obesity: Cause or consequence? Med Hypotheses. 2011; 77:7-10. [PubMed: 21444159]

56. Goodman E, Whitaker RC. A prospective study of the role of depression in the development and persistence of adolescent obesity. Pediatrics. 2002; 110:497-504. [PubMed: 12205250]

57. Hasler G, Pine D, Gamma A, Milos G, Ajdacic V, Eich D, Rossler W, Angst J. The associations between psychopathology and being overweight: a 20-year prospective study. Psychol Med. 2004:1047-1057. null. [PubMed: 15554575]

58. Hicken M, Lee H, Mezuk B, Kershaw K, Rafferty J, Jackson J. Racial and ethnic differences in the association between obesity and depression in women. J Women's Health. 2013; 22:445-452. 
59. Uebelacker L, Strong D, Weinstock L, Miller I. Use of item response theory to understand differential functioning of DSM-IV major depression symptoms by race, ethnicity and gender. Psychol Med. 2009; 39:591-601. [PubMed: 18588740]

60. Lewis-Fernandez R, Das A, Alfonso C, Weissman M, Olfson M. Depression in US Hispanics: diagnostic and management considerations in family practice. J Am Bd Fam Med. 18:282-296.

61. Mozaffarian D, Hao T, Rimm E, Willett W, Hu F. Changes in diet and lifestyle and long-term weight gain in women and men. N Engl J Med. 2011; 364:2392-2404. [PubMed: 21696306]

62. Lin B-H, Huang C, French S. Factors associated with women's and children's body mass indices and income status. Int J Obes. 2004; 28:536-542.

63. Jeffery R, Finch E, Linde J, Simon G, Ludman E, Operskalski B, Rohde P, Ichikawa L. Does clinical depression affect the accuracy of self-reported height and weight in obese women? Obesity. 2008; 16:473-475. [PubMed: 18239662]

64. Eicher-Miller H, Mason A, Abbott A, McCabe G, Boushey C. The effect of food stamp nutrition education on the food insecurity of low-income women participants. J Nutr Educ Behav. 2009; 41:161-168. [PubMed: 19411049]

65. Weiss D, O'Loughlin J, Platt R, Paradis G. Five-year predictors of physical activity decline among adults in low-income communities: a prospective study. Int J Behav Nutr Phys Act. 2007; 4:2-7. [PubMed: 17233904] 


\section{Table 1}

Demographic, Food-Related Indicators, Health Indicators, and Self-Reported Weight Characteristics of LowIncome Mothers $(\mathrm{n}=166)$

\begin{tabular}{|c|c|c|}
\hline Characteristics & Prevalence of characteristic $\%$ or $m(S D)$ & Range \\
\hline \multicolumn{3}{|l|}{ Socio-Demographic Covariates } \\
\hline Education $<12^{\text {th }}$ grade & $56.1 \%$ & \\
\hline Employed & $74.5 \%$ & \\
\hline \multicolumn{3}{|l|}{ Monthly Household Income } \\
\hline Less than $\$ 1,000$ & $34.9 \%$ & \\
\hline$\$ 1,000$ to $\$ 1,500$ & $23.2 \%$ & \\
\hline Greater than $\$ 1,500$ & $39.2 \%$ & \\
\hline Missing & $0.6 \%$ & \\
\hline \multicolumn{3}{|l|}{ Ethnicity } \\
\hline Hispanic & $55.4 \%$ & \\
\hline Black & $12.7 \%$ & \\
\hline White & $22.3 \%$ & \\
\hline Other & $9.0 \%$ & \\
\hline Missing & $0.6 \%$ & \\
\hline \multicolumn{3}{|l|}{ Marital Status } \\
\hline Single & $62.7 \%$ & \\
\hline Married & $31.3 \%$ & \\
\hline Divorced & $3.6 \%$ & \\
\hline Widowed & $1.2 \%$ & \\
\hline Missing & $1.2 \%$ & \\
\hline Lives with partner/spouse & $42.8 \%$ & \\
\hline Spanish primary language at home & $25.3 \%$ & \\
\hline Ever Breastfed focal child & $62.8 \%$ & \\
\hline Maternal age in years $m(S D)$ & $30.1(7.2)$ & $18-55$ \\
\hline Maternal education in years $m(S D)$ & $12.6(3.1)$ & $3-22$ \\
\hline Number of other adults in home $m(S D)$ & $0.9(0.8)$ & $0-5$ \\
\hline \multicolumn{3}{|l|}{ Food-Related Indicators } \\
\hline \multicolumn{3}{|l|}{ Food Assistance Programs } \\
\hline Receives WIC ${ }^{a}$ & $59.0 \%$ & \\
\hline Receives SNAP ${ }^{b}$ & $61.4 \%$ & \\
\hline Uses community food programs ${ }^{c}$ & $16.9 \%$ & \\
\hline Times/week shopped supermarket $m(S D)$ & $2.1(1.6)$ & $0-7$ \\
\hline Food Shopping Practices scale $m(S D)$ & $2.69(0.6)$ & $1-4$ \\
\hline Household Food Insecurity ( $\geq 3$ yes) & $41.6 \%$ & \\
\hline \multicolumn{3}{|l|}{ Health Indicators } \\
\hline CES-D $^{d}$ scores $m(S D)$ & $10.9(8.9)$ & $0-60$ \\
\hline Self-rated health $m(S D)$ & $3.2(1.0)$ & $1-5$ \\
\hline
\end{tabular}




\begin{tabular}{clc}
\hline Characteristics & Prevalence of characteristic \% or $\boldsymbol{m}(\mathrm{SD})$ & Range \\
\hline Maternal weight & & \\
$\mathrm{BMI}^{e} m(\mathrm{SD})$ & $29.0(7.4)$ & $17-59$ \\
Overweight $(30<\mathrm{BMI} \geq 25)$ & $32.5 \%$ & \\
Obese (BMI $\geq 30)$ & $33.1 \%$ & \\
\hline
\end{tabular}

${ }^{a}$ WIC $=$ Special Supplemental Nutrition Program for Women, Infants and Children.

$b_{\text {SNAP }}=$ Supplemental Nutrition Assistance Program.

${ }^{c}$ Community food programs $=$ food banks/pantries and/or soup kitchens.

${ }^{d}{ }_{\text {CES-D }}=$ Center for Epidemiological Studies - Depressions Scale.

${ }^{e} \mathrm{BMI}=$ Body Mass Index . 


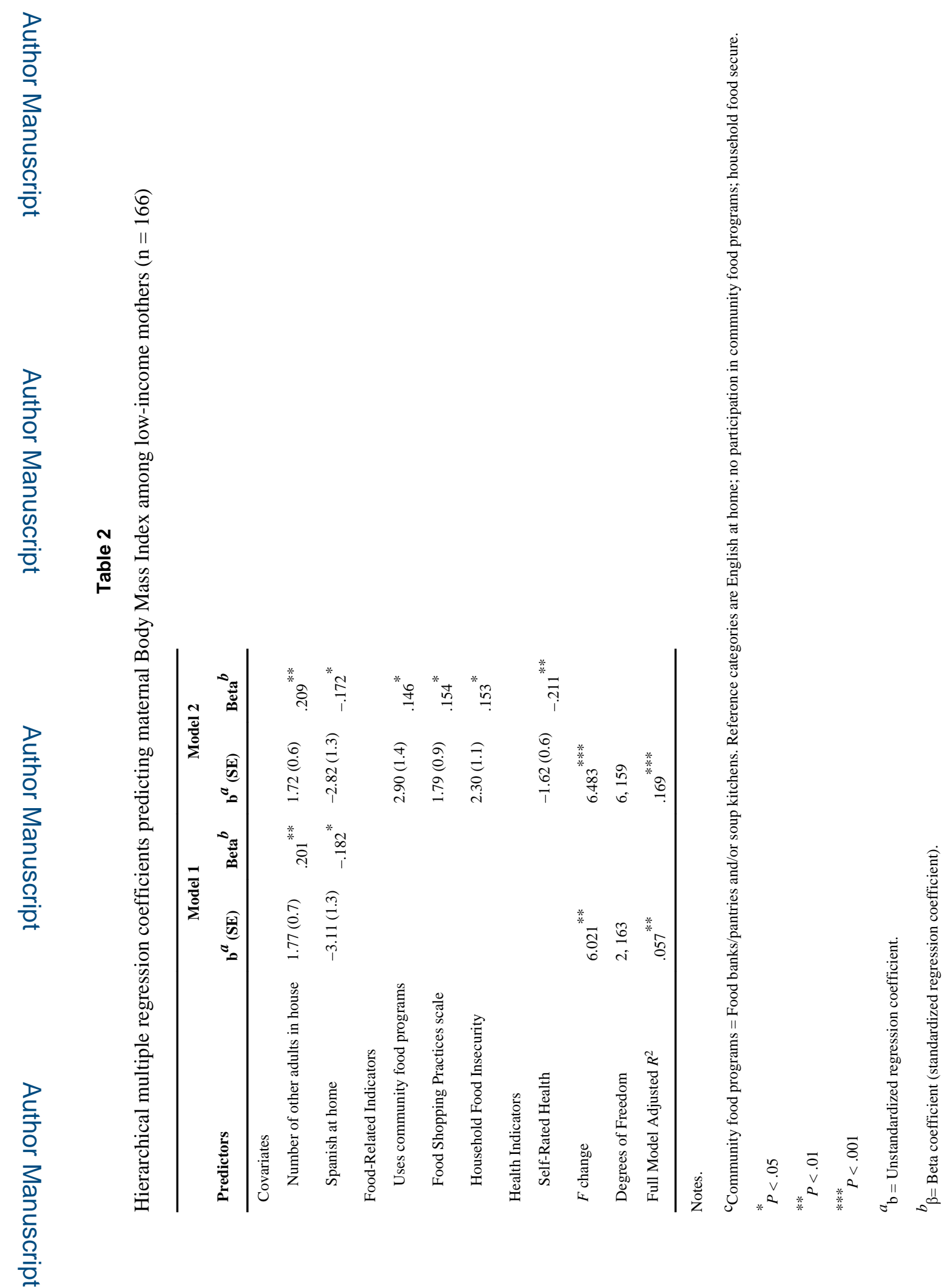

J Nutr Educ Behav. Author manuscript; available in PMC 2016 May 01. 